\title{
APPLICATION OF LOGISTIC MODELS FOR STOCK MARKET BUBBLES ANALYSIS
}

\author{
Stasys Girdzijauskas ${ }^{1}$, Dalia Štreimikienė ${ }^{2}$ \\ Vilnius University, Kaunas Faculty of Humanities, \\ Muitinès g. 11, LT-44280 Kaunas, Lithuania \\ E-mails: ${ }^{1}$ stasys.girdzijauskas@vukhf.lt; ${ }^{2}$ dalia@mail.lei.lt \\ Received 9 August 2007; accepted 15 November 2008
}

\begin{abstract}
The article deals with economic bubbles and analyses their possible causes and tools for the prediction of such bubbles development. An economic bubble is the commonly used term for an economic cycle that is characterized by a rapid expansion followed by a dramatic crash. While some bubbles happen naturally as a part of the economic cycle, some also occur as a result of investor exuberance and serve as correctives. These typically happen in securities, stock markets, real estate and various other business sectors because of certain changes in the way key players conduct business. The well-known and widely discussed bubbles in asset markets were analysed and compared trying to define the main features, causes and signals of such bubbles creation: Dotcom, Telecom, Health South Corporation, NASDAQ, etc. These bubbles were analysed in the article by applying the logistic growth model allowing to predict the bubbles creation as a result of growth satiation in the conditions of limited resources.
\end{abstract}

Keywords: stock market bubble, logistic growth model

\section{Introduction}

A stock market bubble in the financial markets is the term that is applied to a self-propagating rise or increase in the share prices of stocks in a particular industry or sector. The term "stock market bubble" can only be used with any certainty in retrospect when share prices have since fallen drastically or crashed. A bubble happens when speculators notice the swift rise in value of stocks and then decide to buy more of the same stocks as a way of anticipating further rises rather than because the shares have been undervalued. This buying spree results in many companies' shares becoming grossly overvalued creating a widening discrepancy between the share price and the actual value of the stocks. When the bubble bursts the share prices will fall very swiftly and dramatically, with the falling prices trying to seek the fundamental value of the stocks. This can actually result in many companies going out of business.

There are several recent investigations of economic growth and implications of sustainable development concept on economic growth performed in Lithuania
(Grundey 2008; Zavadskas 2008). In most cases, the growth of economy, or growth of the capital is not subject to any restrictions, however EU environmental policies, etc. put some restrictions on economic growth (Štreimikienè, Esekina 2008) because of limited capacity of environment to absorb pollution. In general, from the theoretical perspective, capital is considered to be of unlimited growth. Nevertheless, such an estimation of capital is not accurate. In the paper, the analyzed capital is related to the finite resources of growth; in other words, it cannot develop endlessly. Thus, the paper focuses on the functions of limited growth, or on logistic functions that describe the process of capital accumulation (i.e. growth).

The specificity of the logistic function lies in its limited growth aspect. To say more, it undergoes alteration exclusively within a described interval: from zero to a particular (maximum) rate. The logistic growth is a characteristic feature not only with respect to capital but, actually, to any population whose rate of growth is proportional to their size. In the following analysis of the capital growth functions, the financial resources will be considered. The resources of capital growth are 
related to some particular environment in which they are invested. Here the resources of capital development are understood as the greatest capital amount which may be invested in such an environment.

On the whole, the logistic models are widely applied for the investigation of the biological systems. In the field of economic enquiry, they have been seldom applied - only single attempts at the analysis of the economic systems have been discovered by the authors (Ferreira 1998; Shone 2001; Sterman 2000). The main drawback of such models is that they do not offer the growth function expressed in compound interest. In Lithuania, the exploration of the mentioned problem started in 2002 (Girdzijauskas 2002; Merkevičius et al. 2006; Girdzijauskas et al. 2007; Girdzijauskas 2008).

The article aims to analyse the origin of stock market bubbles creation based on logistic capital growth model.

\section{Stock market bubbles}

Two major stock market bubbles happened in the late 1990s and early in 2000 in the USA. The soaring market of the 1990s was seen by many economists as the harbinger of a new age sustained, rapid economic growth. The same situation was in 1920. As in the 1990s it was widely claimed that a new economy had taken root in the USA. In both periods, unemployment was low with stable prices in the twenties and low inflation in the nineties. Participation in the market increased, as investing in the market seemed safer, with reduced macroeconomic risk and the seeming abundance of high return opportunities (White 2006).

In both 1920 and 1990 the boom was explained by scientists as driven by technological change raising dividends. The idea of technological age played a key role in the mind of the 1990s' bull market. The rapid changes in computer/information technology and biotechnology were heralded as placing the economy on a higher trajectory. The new era vision was supported by many economists. It was expected that technology would have an even greater impact on productivity growth. Like in the 1920s the conclusion for 1990 was fairly clear - the expected dividend growth was not a major factor driving the boom (Eatwell 2004).

Several articles were published analysing and comparing the situations in 1920 and 1990 and trying to provide the explanations of stock market bubbles (White 2006; Eatwell 2004; Pastor, Veronesi 2004; Cochrane 2002; Caballero, Hammour 2002; Kraay, Ventura 2005; DeLong, Magin 2001).
Different economists provide different explanations. Pastor and Veronesi (2004) studied the NASDAQ bubble and argued that the fundamental value of a firm increases with uncertainty about average future profitability, and this uncertainty was unusually high in the late 1990s. Authors stated, that the models which had been used to value technology stocks omitted an important determinant of the fundamental value, namely the uncertainty about a firm's average future profitability, which can also be thought of as the uncertainty about the average future growth rate of the firm's books value. According to Pastor and Veronesi (2004) the late 1990s witnessed high uncertainty about the average growth rates of technology firms, and that this uncertainty was partly responsible for the high level of technology stock prices. Cochrane (2002) suggested that a mechanism much like the transactions demand for money drove many stock prices above the "fundamental value".

Caballero and Hammour (2002) interpreted a stock market bubble as a high-valuation equilibrium with the low effective cost of capital based on optimism about the future availability of funds for investment. Authors showed in their investigation that such bubbles arise naturally when the expansion is concentrated in the "new economy" sector and when it is supported by sustained financial surpluses, both of which would constitute an integral part, as cause and consequence, of a "speculative growth" equilibrium. The high-valuation equilibrium may take the form of a stock market bubble. In contrast to classic bubbles on non-productive assets, the bubbles in the Caballero and Hammour (2002) model encourage real investments, boost long run savings, and may appear in dynamically efficient economies. In the particular case of the U.S. in the 1990 s, the authors argue that at least two factors created the conditions for a speculative growth episode: the emerging information technology sector and conservative fiscal policy. Both factors created favourable conditions for growth-saving feedback and for the possibility of a speculative equilibrium characterized by extreme stock market valuations and a potential crash. Kraay and Ventura (2005) have provided a joint account of some of the major US macroeconomic events of the past decade: large current account deficits and a steady decline in the net foreign asset position; the large boom and a subsequent crash in the stock market; and the emergence of large fiscal deficits. According to the conventional view, the evolution of the stock market and fiscal deficits are more or less unrelated events, with the former driven by sharp swings in US productivity, and the latter by shifting US political considerations. Both of these, in turn, fuelled current 
account deficits that must eventually be reversed as the accumulation of public debt becomes excessive.

Kraay and Ventura (2005) proposed two alternative views in which the stock market and the fiscal deficits are closely linked. Authors stated that the US economy contains "pockets" of inefficiency. This opens the possibility for asset bubbles to exist, which in turn provides a more plausible explanation for the large swings in equity values over the past decade. The appearance of a bubble in the US stock market in the second half of the 1990s accounts for much of the decline in US net foreign assets during this period. At the same time, the bubble raised welfare worldwide by eliminating inefficient investments.

According to Eatwell (2004) the collapse of the stock market in 2000 was the result of a coordination failure or change in investor sentiment, and the rapid expansion of public debt since then served to displace inefficient investments in the same way that the bubble did. Viewed in this light, the large budget deficits of the Bush administration can be interpreted as a welfareimproving response to this market failure. But there is also a more "cynical" interpretation, that is observationally equivalent to the "benevolent" view. Under this interpretation the expansion of public debt caused the collapse of the bubble, as the US government tried to appropriate the value of the bubble from its US and foreign owners.

White (2006) provides his own comments on the 1920 and 1990 stock market bubbles and criticizes both fundamental approach in forward looking assets and waves of pessimism and optimism driving investors decisions and therefore creation of bubbles, however the author does not provide any reasonable explanations of stock market bubbles and puts more questions than answers.

There were also other examples of bubbles in stock markets. In the autumn of 2002 stock prices of the biggest chain of rehabilitation hospitals in the United States dropped dramatically, after revealed regulatory concerns. On the one hand this case can be put along with the same events concerning Enron, WorldCom, etc. On the other hand, there were differences concerning the reaction of headquarters - just weeks before negative conclusions, which affected a fall of stock prices, the chairman of HealthSouth Corporation sold 94 percent of his company. There is a strong opinion, that the main reasons for this wave of dramas, concerning, as we mentioned above, not only HealthSouth Corporation, but also Enron, WorldCom was technology bubble. It is well-recognized, that the technology bubble has induced, or has been accompanied by, a number of new trends, one of which is the growth in earnings manipulation. The enormous growth in earnings restatements during the 1990 s could be presented as evidence. The main underlying forces that generate and fuel such a bubble, according to the opinion of analysts, rely on three fundamental observations:

1) many investors are not fully rational and exhibit various psychological biases in their financial decisionmaking. Also, some investors may take reported earnings at face value, without looking deeper into a firm's accounts;

2) investors' intrinsic overconfidence generates differences of opinion, since at any given time investors overweigh their own information and at the same time they underweigh others' information.

3) usage of derivatives causes a wider range of possible price speculation. Combination of these three processes allows the possibility of speculation to occur in the market.

However, all observations do not provide the clear explanations of the mechanism of stock market bubble formations, as the process itself is too complex (Tvaronavičienè, Michailova 2006). The Logistic growth models, as authors claim, can be applied to shed more light on stock market bubble formations.

\section{Capital accumulation models}

Most frequently, in the cases when various financial problems occur in relation to payments or cash rate at the given moment of time, or when it is urgent to model the capital price, investments or any other cash flows, the present or future value of capital is calculated. As a rule, such calculations are based on the socalled formula of compound interest (Bodie, Merton 2000). Consider:

$$
K=K_{0} \cdot r^{t},
$$

here: $K_{0}$ is the present capital value; $K$ expresses the future capital value or the capital value at the $t$ moment of time; $r$ describes the coefficient of accumulation rate ( $r=1+i$; here $i$ is interest rate) and $t$ is accumulation duration expressed in time units fixed in interest rate. Sometimes Equation (1) is called an exponential function of capital accumulation.

Traditionally, Equation (1) is used to calculate the growth of capital (population, product). However, much calculation may be performed only until the capital growth is not restricted by external factors (Merkevičius et al. 2006). 
Capital cannot increase at an equal rate endlessly, the more so if the system is completely or partially closed. When growing in such a system, capital exhausts the limited resources in its environment. In other words, it enters into self - competition which diminishes its growth - the system gets 'satiated'.

It is assumed that in the given environment, capital may increase up to a certain limit (in the given environment, only a particular amount of capital not larger than the determined one may be invested). The maximum rate of growth is $K_{m}$. Then the interval of the capital alteration, or growth (relatively, it may be considered as an areal, or space of growth) is as follows $K_{0} \leq K \leq K_{m}$.

The growth of capital will be described by the logistic function of growth (Girdzijauskas 2008). Consider:

$$
K=\frac{K_{m} \cdot K_{0} \cdot r^{t}}{K_{m}+K_{0} \cdot\left(r^{t}-1\right)},
$$

here: $K_{0}$ is the present capital value; $r$ defines the accumulation rate coefficient and $t$ is time expressed in the same units as the time estimated in the interest rate of growth (in most cases, it points to the whole periods of the interest rate recalculation).

It should be noted that if the maximum value of the product $K_{m}$ increases and approaches infinity $\left(K_{m} \rightarrow \infty\right)$, i.e. if for Equation (2) the $\operatorname{limit} \lim _{x \rightarrow \infty} K$ will be calculated, then, as it might have been expected, Formula 2 will turn into an ordinary rule of compound interest (1). Then, the formula of compound interest (1) will make a separate case of the logistic accumulation function (2), when the maximum capital rate $K_{m}$ is extremely high.

In frequent economic calculations, the present capital value rather than the capital growth, i.e. its future value is calculated. Then the logistic function of the present value is used (Girdzijauskas 2008). Consider:

$$
K_{0}=\frac{K_{m} \cdot K}{K+\left(K_{m}-K\right) \cdot r^{t}},
$$

here: $K_{0}$ is the present capital value; $K$ expresses the capital value at the $t$ moment of time; $r$ defines the accumulation duration expressed in the time units fixed in interest rate. Actually, the described expression is the formula of logistic discount.

\section{Elasticity of the logistic internal rate of return to the resources}

It is often important to measure the "sensitivity" of the function revealing the economic phenomenon to the alterations of a particular variable. At first it might seem that an appropriate measure of such sensitivity should be the fall of the function. However, the fall of the function depends on the units by which the argument and the function itself are measured. If the capital is measured by Euros, the fall gets diminished 3.5 times. Therefore, in order to avoid the recurrent consideration of the employed measurement units, it is purposeful to apply the sensitivity measure that does not depend on measurement units. In economics, such measure is called elasticity. The elasticity of the function with respect to argument is an approximate increase of the function in per cent (i.e. its growth or decrease) that conforms to the increase of an independent variable in one per cent.

With respect to time capital elasticity may be expressed as the ratio of time and capital multiplied by the fall of the capital function. Elasticity is also convenient to be described with the use of the function derivative.

It is assumed that the alteration of the independent variable (i.e. argument) $X$ of the function $y=f(x)$ is $\Delta x$ and the alteration of the function $\Delta y$. Then the relative alteration (i.e. increase) of the independent variable will make $\Delta x / x$, and the relative alteration of the function will be $\Delta y / y$. When the function's relative alteration is divided by the argument's relative alteration, the approximate value of elasticity $\operatorname{Ex}(y)$ will be as follows:

$$
E_{x}(y) \approx \frac{\Delta y}{y}: \frac{\Delta x}{x}=\frac{\Delta y}{\Delta x} \cdot \frac{x}{y} .
$$

If in the analyzed interval the function $y=f(x)$ has its derivative, then

$$
\lim _{\Delta x \rightarrow 0}\left(\frac{\Delta y}{\Delta x} \cdot \frac{x}{y}\right)=\frac{x}{y} \lim _{\Delta x \rightarrow 0} \frac{\Delta y}{\Delta x}=\frac{x}{y} \cdot \frac{d y}{d x} .
$$

The obtained expression will be the elasticity of the function $y=f(x)$. Consider:

$$
E_{x}(y)=\frac{x}{y} \cdot \frac{d y}{d x} .
$$

With respect to argument (i.e. time) the function's elasticity is the limit of the function's relative alteration divided by the argument's relative alteration when the argument's alteration approaches zero. To make it shorter, the function's elasticity is the ratio of argument and function multiplied by the function's derivative.

It should be stressed that the function's elasticity is usually described by pointing out the agent with respect to which it is calculated. For instance, in the theory of economics, the elasticity of demand or supply to price, the demand's elasticity to income, etc. is calculated.

Actually, the function whose module of elasticity is higher than 1 , is considered to be elastic. In case its 
module of elasticity is lower than 1 , the function is considered to be non-elastic. If it is equal to 1 , the function demonstrates its single - unit elasticity.

Now the compound interest function's (1) elasticity to time should be calculated. Since the rate of the function's alteration is $d K / d t=K_{0} \cdot r^{t} \cdot \ln r$, its elasticity will make:

$$
E_{t}(K)=t \cdot \ln r .
$$

If the compound interest function (1) is replaced by its separate case - the equation of natural growth $K=$ $K_{0} \cdot e^{i \cdot t}-$ its elasticity will be as follows:

$$
E_{t}(K)=t .
$$

It is obvious that the elasticity of the natural growth function to time is equal to the value of the time from which it is calculated. This function becomes elastic when $t>1$.

Compound Interest Formula (1) is used to discount the sums when the present rate $K_{0}$ is calculated. Since $K_{0}=$ $K / r^{t}$, the elasticity of the present value to time will be as follows:

$$
E_{t}\left(K_{0}\right)=-t \cdot \ln r .
$$

Hence the elasticity of the future and the present values of compound interest differ only by their signs. Meanwhile, the elasticity of the logistic growth function (2) to time is a little more complex. It makes:

$$
E_{t}(K)=\frac{\left(K_{m}-K_{0}\right) \cdot \ln r^{t}}{K_{m}+K_{0} \cdot\left(r^{t}-1\right)}
$$

The elasticity of the logistic present value to time is as follows:

$$
E_{t}\left(K_{0}\right)=-\frac{\left(K_{m}-K\right) \cdot r^{t} \cdot \ln r}{K+\left(K_{m}-K\right) \cdot r^{t}} .
$$

To prove the possibility for the elasticity application during the exploration of the economic bubbles, a particular investment project should be analyzed.

It is assumed that the project will be realized within 5 years. At the beginning of the first year 1 relative monetary unit is invested. Later on, for five years in turn, an adequate part of the monetary unit is invested -0.9 ; $0.8 ; 0.7 ; 0.6$ and 0.5 .

The project's income obtained annually is the same and equal to 1 relative monetary unit. The project's internal returnability may be calculated in the following way. For the analysis of the project the most important is the total cash flow. Here the part of income is an increasing sequence: $0.1 ; 0.2 ; 0.3 ; 0.4$ and 0.5 of the relative monetary unit each year. The sum total is positive and makes 0.5 of the monetary unit.

With the use of Computer Calculator Microsoft Excel it is found out that the project's internal rate of return is $I R R=0.12$.

The analogical logistic internal rate of return will differ from the calculated one and will depend on the amount of the capital resources. For each particular limited capital $K_{m}$ it is found out from the following equation:

$$
\operatorname{LIRR}=\sum_{j=1}^{5} \frac{K_{m} \cdot K_{j}}{K_{j}+\left(K_{m}-K_{j}\right) \cdot r^{j}}-1,
$$

here: $L I R R$ is logistic internal rate of return; $K_{j}$ is the $j^{t h}$ member of the money flow ( $j$ also defines the accumulation duration expressed in time units fixed in the interest rate $i ; j=\overline{1,5}), r$ is accumulation rate coefficient with the interest rate $i(r=1+i)$.

Then the dependence of the investment project's logistic internal rate of return on the amount of the limited capital resources is calculated. It should be noted that the dependence is further presented in the form of the table (Table 1). To perform the analytical research, the regression equation of this dependence should be worked out. Consider:

Table 1. Dependence of the logistic internal rate of return on the amount of resources

\begin{tabular}{lccccccccccc}
\hline$K_{m}$ & 0.497 & 0.5 & 0.51 & 0.52 & 0.55 & 0.6 & 0.68 & 0.8 & 1 & 2 & 20 \\
\hline LIRR & 0.66 & 0.66 & 0.49 & 0.44 & 0.36 & 0.30 & 0.25 & 0.21 & 0.18 & 0.14 & 0.12
\end{tabular}

It is assumed that $L I R R=y$. Then the regression curve equation of the dependence of the internal rate of return on the amount of the capital resources is as follows:

$$
y=0.12+0.0125 \cdot\left(K_{m}-0.4\right)^{-1.573} .
$$

The derivative of this function is worked out in the following way:

$$
\frac{d y}{d K_{m}}=\frac{-0.01966}{\left(K_{m}-0.4\right)^{2.573}} .
$$

Then the elasticity of the internal rate of return to resources will make:

$$
E_{K_{m}}(y)=\left|\frac{-0.01966 \cdot K_{m}}{0.12 \cdot\left(K_{m}-0.4\right)^{2.573}+0.0125 \cdot\left(K_{m}-0.4\right)}\right|,
$$

here: $K_{m}>0.4$. When the limited capital is lower than 0.7904 , the elasticity of the project's logistic internal rate of return is higher than 1 , which means that the internal rate of return has become elastic (or sensitive). 


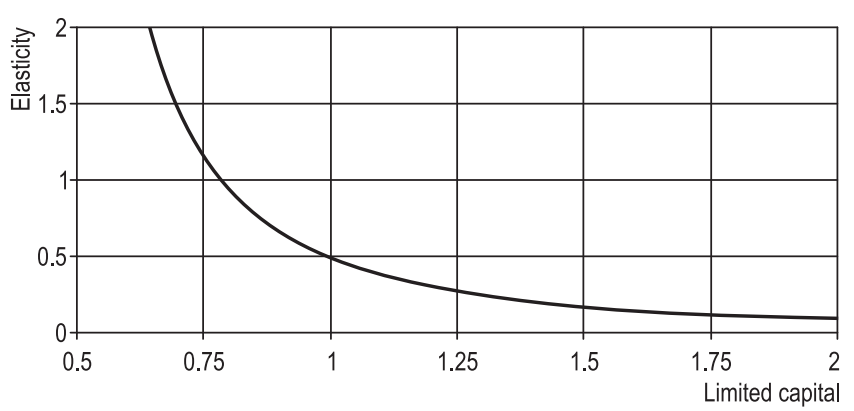

Elasticity of the logistic internal rate of return to the limited capital in the discussed investment project

With the further decrease of the limited capital and its approaching the limited value that makes 0.4 of the relative monetary unit, the elasticity turns to be as high as it is desired. It means that the project itself turns into a price bubble. For instance, when $K_{m}=0.42$, the value of elasticity found out on the basis of Formula (6) makes 32 units; when $K_{m}=0.41$, the elasticity value makes already 64 units. In other words, when the limited capital alters by 0.01 of the relative monetary unit, the elasticity alters by approximately 32 units. Then, on the theoretical level, it is possible to illustrate the price bubble formation. On the practical level, the price bubble may explode without having reached such high elasticity values.

The analyzed example shows that the decrease of resources that is more frequently noticed in a closed system considerably alters the behaviour of the investment environment: with the decrease of the growth recourses the internal rate of return increases. In turn, the growth of the internal rate of return causes the critical increase of the system's efficiency. The system becomes unstable so that with an inconsiderable alteration of the value of the resource rate may destroy the system itself. Hence the project's logistic internal rate of return elasticity to the limited capital (Figure) shows the stability degree of the forming stock market bubble. The very high increase of internal rate of return was the main characteristic of stock price bubbles manifested in 1920 and 1990. The application of logistic growth models for economic bubbles analysis needs to be explored further seeking to develop an effective tool for the prediction of stock and other markets bubbles.

\section{Conclusions}

There are many explanations of economic and stock market bubbles provided in scientific literature which are mainly based on fundamental value approach, inflation, waves of pessimism and optimism driving investors decisions in stock markets, etc., however all these approaches do not provide clear explanations of the origin of stock market bubble formations.
Exponential models are widely employed to model the alteration of the permanently growing capital. However, such models are not always fit for the practical use because of their insufficient accuracy and convenience. Hence the growth of the capital may be modeled with the use of the logistic growth models. Such logistic models of capital accumulation reveal the dynamics of the capital growth more accurately.

Based on Logistic growth models the growth of the internal rate of return on insvestments causes the critical increase of the system's efficiency. The system becomes unstable and the inconsiderable alteration of the value of the resource rate may destroy the system itself. Hence the project's logistic internal rate of return elasticity to the limited capital shows the stability degree of the forming stock market bubble. The very high increase of internal rate of return was the main characteristic of stock price bubbles manifested in 1920 and 1990.

The method of the logistic investment management allows for a new treatment of the investment assessment and description of the reasons for the possible unsuccessful investment realization. The estimation of the degree of market saturation allows for a more accurate calculation of the rate of return necessary for investment.

\section{References}

Bodie, Z.; Merton, R. C. 2000. Finance. New Jersey: Cambridge University Press. 592 p.

Caballero, R. J.; Hammour, M. L. 2002. Speculative growth. NBER Working Paper No. 9381. Available from Internet: $<$ http://www.nber.org/papers/w9381>.

Cochrane, J. H. 2002. Stocks as money: convenience yield and the tech-stock bubble. NBER Working Paper No. 8987, Cambridge. Available from Internet: $<$ http://www.nber.org/ papers/w8987 >.

Eatwell, J. 2004. Useful bubbles, Contributions to Political Economy 23: 35-47.

Ferreira, O. C. 1998. Capital accumulation in the Brazilian economy, Economy and Energy 9: 1-24.

DeLong, J. B.; Magin, K. 2001. A short note on the size of the Dot-Com bubble. NBER Working paper No. 8630. Available from Internet: <http://www.nber.org/papers/w8630>.

Girdzijauskas, S. 2002. Logistiniai (ribiniai) kaupimo modeliai [Logistic (marginal) accumulation models], Informacijos mokslai [Information Sciences] 23: 95-102.

Girdzijauskas, S. 2008. Logistic theory of capital management: deterministic methods, Transformations in Business and Economics 7, 2(14, Supplement A): 15-163. 
Girdzijauskas, S.; Čepinskis, J.; Jurkonytè, E. 2007. Modern accounting method in insurance tariffs - novelty on the insurance market, Technological and Economic Development of Economy 13(3): 179-183.

Grundey, D. 2008. Application of sustainability principles in economy, Technological and Economic Development of Economy 14(2): 101-106.

Kraay, A.; Ventura, J. 2005. The Dot-Com bubble, the Bush deficits, and the U.S. current account. NBER Working paper No. 11543. Available from Internet: <http://www.nber.org/ papers/w121543>.

Merkevičius, E.; Garšva, G.; Girdzijauskas, S. 2006. A hybrid SOM-Altman model for bankruptcy prediction, Lecture Notes in Computer Science 3994: 364-371.

Pastor, L.; Veronesi, P. 2004. Was there a NASDAQ bubble in the late 1990s? Available from Internet: <faculty.chicagogsb.edu/lubos.pastor/research/bubble14www.pdf $>$.

Shone, R. 2001. An introduction to economic dynamic. London: Cambridge University Press.
Sterman, J. D. 2000. Business dynamics: systems thinking and modelling for a complex world. New York: Irwin/McGraw-Hill. 1008 p.

Štreimikiene, D.; Esekina, B. 2008. EU emission reduction strategies and their impact on atmospheric emissions in Lithuania, Technological and Economic Development of Economy 4(2): 162-170.

Zavadskas, E. K. 2008. Beginning a new stage of development, Technological and Economic Development of Economy 14(3): 241-243.

White, E. N. 2006. Bubbles and busts: the 1990s in the mirror of the 1920s. NBER Working Paper No. 12138. Available from Internet: <http://www.nber.org/papers/w12138>.

Tvaronavičienè, M.; Michailova, J. 2006. Factors affecting securities prices: theoretical versus practical approach, Journal of Business Economics and Management 7(4): 213-222. 